Niteliksel Calıșma

\title{
Engelli Bir Üniversite Öğrencisinin Deneyimleri: İki Farklı Analiz Yöntemiyle Değerlendirme
}

\author{
Müjde KOCA-ATABEY ${ }^{*}$, Bahar ÖZ ${ }^{2}$ \\ 1İstinye Üniversitesi, Fen Edebiyat Fakültesi, Psikoloji Bölümü, İstanbul, Türkiye \\ ${ }^{2}$ Orta Doğu Teknik Üniversitesi, Fen Edebiyat Fakültesi, Psikoloji Bölümü, Ankara, Türkiye
}

\section{Makale Bilgisi \\ Anahtar \\ kelimeler: \\ engelli üniversite öğrencisi, engelin sosyal modeli, yorumlayıcı fenomonolojik analiz, söylem analizi, yaşanmış deneyimler}

Keywords: disabled university student, social model of disability, interpreative phenomenological analysis, discourse analysis, lived experiences

\begin{abstract}
$\ddot{\text { Öz }}$
Literatürde engel ile ilgili farklı bakış açıları mevcuttur. Bunların en bilinenleri tıbbi model, sosyal model ve biyopsikososyal modeldir. Bu çalışma; engeli, hayatın bir gerçeği, değişik bir yaşam deneyimi, ilginç ve müspet bir olgu olarak tanımlayan sosyal model çerçevesinde kurgulanmıştır. Bu çalışma kapsamında, engelli bir üniversite öğrencisinin eğitim hayatıyla ilgili deneyimlerinin incelemesi amaçlanmıştır. İlk aşamada, katılımcı ile 55 dakika süren bir görüşme yapılmış ve konuşulanlar kelimesi kelimesine yazıya aktarılmıștır. Daha sonra ise iki farklı nitel analiz yöntemi (yorumlayıcı fenomonolojik analiz -YFA- ve söylem analizi) bir arada kullanılarak analizler yapılmıştır. Kullanılan iki analiz yöntemi engelli bir üniversite öğrencisi olmanın farklı boyutlarında benzer bulgular ortaya çıkarmıştır. Örneğin 'engelli olmanın adil olmadığı' ile ilgili husus hem YFA hem de söylem analizi sonucunda ortaya çıkmıştır. İki analizin sonuçları karşılaştırıldığında ortaya çıkan en büyük fark, olumsuzlukların söylem analizi sonucunda daha çok kendini göstermesidir. Katılımcının deneyimleri anlamlandırılmaya çalışılırken hem içeriğe hem de bu içeriğin nasıl ifade edildiğine odaklanılmıştır. Bu özellikleriyle, tek katılımcının dâhil edildiği bu çalışma, iki farklı analiz yönteminin kullanımı sonucunda elde edilecek bulguları yorumlama konusunda pilot çalışma niteliğinde bir araştırma olarak kabul edilebilir. Sonuçlar, sosyal model bakış açısıyla incelendiğinde ise toplumun katılımcıya pek çok engel çıkardığı sonucuna varılabilir. Bunun yanında, şartlar ve zaman katılımcının lehine işlemiştir. Engelli üniversite öğrencileri ile ilgili çalışmaların devam etmesi özellikle psikolojik iyilik hallerinin geliştirilmesi açsından önemlidir. Pastanın kreması olarak nitelendirilebilecek bu öğrencilerinin desteklenmesi toplum refahına katkı sağlayacaktır.

Abstract

The literature consists of different perspectives relating disability. The most known models are the medical model, social model and biopsychosocial model. This study is conceptualized within the social model perspective, which argues that disability is a fact of life, a different life experience and it might also be interesting and affirmative. It is aimed to investigate the experience of a disabled university student. Initially a 55minutes interview was conducted and transcribed verbatim. Afterwards, with the usage of two different qualitative methods (interpretative phenomenological analysis -IPA- and discourse analysis), a quest for meaning was started. The two different methods revealed similar results. These results, focusing on relation based, emotional, and coping like different aspects of being a disabled university student, were presented in detail. The results were discussed in relation to the well-being and quality of life characteristics of disabled people. Particular emphasis was placed on the results' potential contribution to the intervention programs on improvement ofwell-being and quality of life of disabled university students.
\end{abstract}

*Sorumlu Yazar, İstinye Üniversitesi, Psikoloji Bölümü, Topkapı Kampüsü, Maltepe Mah., Edirne Çırpıcı Yolu, No.9

Zeytinburnu, İstanbul. . Tel: (o 850) 28350 00; Fax: (o 212) 4813688

e-posta: mujde.koca.atabey@gmail.com; matabey@istinye.edu.tr

Gönderim Tarihi (Received): 28.05.2018; Kabul Tarihi (Accepted): 21.06.2018

DOI: $10.31682 /$ ayna.427561

2148-4376 / All rights reserved. 


\section{Giriş}

Bugüne kadar farklı bağlamlarda yapılmış engel ile ilgili çalışmalara bakıldığında, ilgili alanyazında farklı bakış açılarının mevcut olduğu görülmektedir. Bunlardan en eskisi tıbbi modeldir. Tıbbi modele göre engel bir hastalıktır ve engelli kişi de tedaviye muhtaç bir konumundadır (Oliver, 1996; Ong-Dean, 2005). Bunun yanında, 1970 `lerde İngiltere'de ortaya çıkan sosyal model, engelin asıl nedeninin kişiden değil toplumdan kaynaklandığını savunur (Barnes ve Mercer, 2003; Morris 1993). Bu modele göre konuşamama bir fiziksel sorunsa, gerekli teknik donanım sunulmamasından kaynaklanan iletişim kuramama durumu bir engeldir; kişinin durumundan ziyade, fiziksel, sosyal ve psikolojik bariyerler engeli yaratır (Morris, 1993). Bu bakış açısına göre, konunun uzmanı da engelli kişinin kendisidir (Oliver, 1996). Sosyal model, içinde bulunulan kültürün de engeli tanımlamadaki anlamlı etkisine (Priestly, 2003) ve kişi toplumsal dışlanma nedeniyle “engellenmiş” olduğuna (UPIAS, 1975) vurgu yapar. Bu bakış açılarının yanı sıra, Amerika temelli biopsikososyal model engeli bir bütünsellik içinde açlklar (WHO, 2002); ancak, eklektik olmayı amaçlayan ve "fazla olan iyidir” bakış açısı ile düzenlenen bu model de her zaman ve durum için geçerli sonuçlar vermeyebilir (Ghaemi, 2009). Literatürde engel ile ilgili olarak karşımıza çıkan diğer iki model, kişisel model ve trajedi modelidir. Adı geçen iki modelin de engeli yorumlamada yetersiz kaldığı söylenebilir. Kişisel model, engeli kişinin problemi olarak tanımlar; trajedi modeline göre ise engelli kişi ya zavallı ya da süper kahramandır. Her iki bakış açısıyla da engel, tek yönlü dar bir perspektifle normalin veya yaşanan gerçek yaşantının dışına çıkarılıp açıklanmaya çalışılmıştır (French 2004; Oliver, 1996). Bu çalışma; engeli, hayatın bir gerçeği, değişik bir yaşam deneyimi, ilginç ve müspet bir olgu olarak tanımlayan sosyal model kapsamında kurgulanmıştır (bkz. French ve Swain, 2004; Morris, 1991; Oliver, 1996). Bu noktada belirtilmesi gereken önemli bir husus da kullanılan dil ile ilgilidir. Yaygın ve nispeten yerleşmiş olduğundan çalışma kapsamında "engelli kişi” (person with a disability) ifadesi kullanılmaktadır fakat kavramsal olarak arkasında durulan bakış açısı "engellenmiş kişi” (disabled person) yönündedir. Bunun sebebi, çalışma kapsamında Davis ve Green in (1999) de vurguladığı gibi engelin kişinin taşıdığı bir bavul parçası olmadığı, aksine kişinin çevresi ve toplum tarafından engellendiği görüşünün savunulmasıdır.

Engel, eğitim (örn. Barnes, 2007; Koca-Atabey, Karancı, Dirik, Aydemir, 2011), çalışma ortamı (örn. Humber, 2014), trafik ortamları (örn. Bakır, 2016; Koca-Atabey ve Öz, 2017) gibi çeşitli alanlarda çalışılmış ve engelin bu alanlarda kişilerin yaşadığı tecrübeler, hayat kaliteleri ve genel iyilik halleri gibi konulara direk veya dolaylı etkileri olduğuna değinilmiştir. Özellikle insanların temel hakları ile ilgili alanlar göz önünde tutulduğunda engellenmiş bir bireyin yaşadığı sıkıntılar ve sonuç olarak yaşadığı psikolojik ve teknik 
sorunlar daha farklı bir önem kazanmaktadır. Eğitim bu temel haklardan, eğitim ortamları da bu alanlardan biridir. Holloway (2001) eğitimde engelin ders ile ilgili bilgiye ulaşamamaktan kaynaklandığını söyler. Engelli üniversite öğrencisinin pek çok sorunu vardır. Kalacak yer, ulaşım (örn. Soorenian, 2013), fiziksel çevrenin uyumsuzluğu (örn. Redpath, Kearney, Nicholl, Mulvenna, Wallace ve Martin, 2013), kütüphaneyi ve yemekhaneyi kullanma (örn. Dökmen ve Tutarel-Kışlak, 2004) ile ilgili somut sorunların yanında sosyal sınırlamalar ve tutumlardan kaynaklanan sorunlar da engelli üniversite öğrencilerinin (örn. Fuller, Healey, Bradley ve Hall, 2004; Goode, 2007; Redpath vd., 2013) hayatlarını zorlaştırmaktadır. Siralanan bu sorunların, ilk etapta düşünüldüğünde engelli üniversite öğrencileri ile engelli olmayan üniversite öğrencilerinin benzer şekilde yaşadığı problemler olduğu düşünülebilir; oysa daha detaylı bakıldığında engelli öğrencilerin engelli olmayan öğrencilerle aynı konularda yaşadıkları problemlerin daha yoğun, fazla veya farklı içeriklere sahip problemler olabileceği görülmektedir (Hopkins, 2011). Engelli üniversite öğrencilerinin deneyimlerini şekillendiren en önemli unsurlardan biri kendilerine sunulan ya da sunul(a)mayan imkânlardır (Koca-Atabey, 2013; Koca-Atabey vd., 2011; Poussu-Olli, 1999). Engelli üniversite öğrencileri, hayatlarının erken yetişkinlik döneminin başlarında hayata yeni atılmış, akademik ortam ve görevlerine uyum sağlama çabasının yanında engelin getirdiği psikolojik, sosyal ya da fiziksel sorunlarla da boğuşan bireylerdir. Engelli olsun veya olmasın üniversite öğrencilerinin eğitimlerine başladıkları yaşların aynı zamanda madde kullanımı, internet bağımlılığı gibi çeşitli problemli davranışların sergilenmeye başlandığı; depresyon ve kaygı gibi psikolojik sağlık problemlerinin görülme sıklığının arttığı yaşlara denk gelmesi bu grubun genel olarak "riskli grup" olarak nitelendirilmesine sebep olmuştur (Wynaden, Wichmann ve Murray, 2013). Üniversite yıllarında bu örüntünün gözlemlenmesinin kişiler için hayat kalitesi düşüklüğü, akademik başarısız ve düşük hayat tatmini gibi şekillerde sonuçlanması yüksek olasıllkta görülmektedir (Eisenberg, Golberstein ve Hunt, 2009). Engelli üniversite öğrencilerine bakıldığında, tüm öğrencilerin yaşadığı genel akademik ve sosyal adaptasyonun yanında maruz kaldıkları engellenmişlik ile ilgili adaptasyonlarının hayat yüklerini artırmakta ve psikolojik sağlıklarını etkilemekte olduğunu göz önünde bulundurmak gereklidir. Bir başka deyişle, bahsedilen genel "riskli grup" içinde yer alan engelli üniversite öğrencilerinin yaşantılarının ve deneyimlerinin detaylı bir şekilde anlamlandırılmasının, bu grubun hayata adaptasyon sürecini ve yaşanan zorluklarını anlamak açısından oldukça değerli olduğu görülmektedir. Bugüne kadar engelin eğitim sektöründe çalışıldığı pek çok çalışma bulunmaktadır (örn. Koca-Atabey vd., 2011; Laes ve Westerlund, 2018; Martins, Borges ve Gonçalves, 2017). Bu çalışmalar incelendiğinde, bu konudaki alanyazının farklı özelliklerde öğrenci veya öğrenci gruplarının katılımcı olarak dahil edildiği, nicel ve nitel yöntemlerin kullanıldığı araştırmalardan oluştuğu görülmektedir. 
Nicel yöntemlerin kullanıldığı analizler geniş örneklemden veri toplanıp yorumlanmasını sağlasa da araştırmacıya altta yatan sebepler, süreçler, çeşitli anlamlandırmalar ile ilgili detaylı bilgi sağlayamamaktadır. Nitel analiz yöntemlerinin temelinde anlam yatar. Bu yöntemin kullanımındaki temel amaç katılımcıların deneyimlerini anlayabilmektir (Willing, 2001). Nitel analizde araştırmacı ile katılımcı arasında direk, yakın ve derin bir iletişim vardır (Hammersley, 1996). Daha zengin bir anlayış elde edebilmek, bütün resmi görmek, kelimeleri duymak, etkileşimleri gözlemlemek ve bağlamı incelemek açısından da dinamik, derin, yaratıcı ve yeniden tanımlayıcı olan nitel analizin (Taylor ve Bogdan, 1998; Zambo, 2004) kullanımı uygun görülmüştür.

Bu çalışma kapsamında, iki farklı nitel analiz yöntemini bir arada kullanarak bir engelli üniversite öğrencisinin üniversite ortamındaki yaşantısı, tecrübeleri, duyguları, düşünceleri ile ilgili derinlemesine bir anlam arayışına çıkılmıştır. Bu amaç çerçevesinde engelli üniversite öğrencisinin deneyimlerini incelerken, yöntemsel farklılıkları ortaya koymak ve bulgularda oluşan değişiklikleri yorumlayabilmek hedeflenmektedir. Bu yönüyle çalışma açıklayıcı ve deneysel olarak nitelendirilebilir. Bu çalışmada, engelli öğrenci olma deneyimlerinin üniversite eğitimi seviyesinde incelenmesinin ve iki farklı nitel analiz yönteminin kullanımının sağlayacağı detaylı anlamlandırmanın sunulması amaçlanmaktadır.

\section{Yöntem}

\section{Katılımeı}

Bu çalışma İngiltere'de yapılmıştır. Katılımcı, 19 yaşında tarih bölümünde lisans eğitimine devam eden, İngiliz kadın bir üniversite öğrencisidir. Vücudunun sol tarafı sağa oranla daha zayıftır, sol kolunu kullanmamaktadır, sol bacağını ve ayağını kullanırken de zorlanmaktadır. Fiziksel problemlerin temelinde serebral palsi (beyin felci) yatmaktadır.

\section{İşlem}

Katılımcıya üniversitenin engel ofisi koordinatörü (disability office coordinator) aracılıyla ulaşılmıştır. Katılımda gönüllülük esastır. Görüşmeye başlamadan önce katılımcıya araştırmanın amaçları açıklanmış; gizlilik ve etik ile ilgili detaylar netleştirilmiştir. Katılımcının tanınma riskinden bahsedilmiştir. Bu husus, özellikle katılımcı sayısının az olduğu nitel çalışmalarda ortaya çıkabilmektedir (Damianakis ve Woodford, 2012; Morse, 1998). Katılımcıya verilen takma ad Lisa'dır. Görüşme esnasında ses kaydı alınmış ve konuşulanlar kelimesi kelimesine yazıya aktarılmıştır; yazıya aktarıldıktan sonra veriler 
katılımcı ile paylaşılmış, içerik doğruluğu teyit edildikten sonra analizlere başlanmıştır (bkz. Whittington ve Burns, 2005).

\section{Veri Toplama Aracı ve Veri Analizi Yöntemleri}

Katılımcıya engelli bir üniversite öğrencisi olmanın nasıl bir deneyim olduğunu anlamak üzere yöneltilebilecek bir takım genel sorular hazırlanmıştır. Sorulan soruların ilki ve en genel olanı “Bir üniversite öğrencisi olarak engelli olmak nasıl bir şeydir?” sorusudur. Bu soruyu katılımcının kendi özgür konuşma ve ifade şeklinin desteklenmesi için kendi tercih ettiği içerik ve hıza göre doğal bir konuşma ortamında cevaplaması beklenmiştir. Daha sonra aynı uygulama şekliyle "Engelinizi nasıl tanımlarsınız? Üniversite kapsamında sunulan desteklerden bahseder misiniz? Üniversitede engel ile ilgili başınıza gelen/tanık olduğunuz olumlu uygulamalar nelerdir? Üniversite ortamında yaşadığınız zorluklardan engelli olmak ile ilişkilendirebilecekleriniz var mıdır?” soruları katılımcıya kendi doğal cevaplama süreç ve tercihlerine göre cevaplanmak üzere yönlendirilmiştir. Katılımcı ile bu sorular üzerinden 55 dakika süren yarı-yapılandırılmış bir görüşme yapılmıştır.

Araştırmada iki farklı nitel analiz yöntemi bir arada kullanılmıştır. Kullanılan ilk analiz yöntemi Yorumlayıcı Fenomonolojik Analiz'dir (YFA). YFA doğası gereği öznel ve araştırmacının katkısını gerekli kılacak şekilde katılımcının belli bir konudaki görüşünü araştırmayı amaçlar (Smith, Jarman ve Osborn, 1999). Katılımcıların kişisel ve sosyal dünyalarını nasıl anlamlandırdığı araştırma sorusu ışığında yorumlayıcı bir biçimde incelenir; yaşanmış deneyimleri araştırmacının bakış açısıyla yorumlamak esastır. Esneklik gerektiren bir yöntem olan YFA için en uygun veri toplama aracı yarı-yapılandırılmış görüşmelerdir (Smith ve Osborn, 2003). YFA'nın üç temel özelliği vardır. Bunların birincisi görüşmelerin detaylı bir şekilde analiz edilmesidir. Bir diğeri tümevarımsal, esnek ve kolaylaştırıcı olmasıdır. Son özellik ise sonuçların literatür ışığında değerlendirilmesidir (Mayers, Leavey, Vallianatou, ve Barker, 2007; Pringle, Drummond, McLafferty, ve Hendry, 2011; Smith, 2004). YFA temelde sağlı psikolojisi çalışmalarında kullanılmak üzere geliştirilmiştir ve en çok kullanıldığı alan hastalık deneyimleridir (Smith 1996; 2011). YFA'nın temel amacının tüm katılımcıların tamamen ve derinlemesine değerlendirilmesi olması sebebiyle örneklemler genel olarak az sayıda katılımcıdan oluşmaktadır. Katılımcı sayısı ile ilgili bir kural bulunmamaktadır, bu karar yapılacak analizin derinliği, tek tek katılımcılardan gelen verinin zenginliği ve araştırmacının katılımcıları ne şekilde değerlendirmeyi veya karşılaştırmayı planladığı gibi faktörlere bağlıdır. Bu temelde, bu çalışmada olduğu gibi tek katılımcının yer aldığı YFA çalışmalarını da; 15 katılımcının yer aldığı çalışmaları görmek mümkündür (bkz. Pietkiewicz ve Smith, 2014). YFA'nın kullanıldı̆̆ı ve tek bir katılımcının 
yer aldığı araştırmalara, bir itfaiyecinin grev deneyimlerinin incelendiği çalışma örnek gösterilebilir (Brunsden ve Hill, 2009).

$\mathrm{Bu}$ çalışma kapsamında kullanılan diğer analiz yöntemi ise söylem analizidir. Söylem analizi dili bağlam çerçevesinde değerlendirir ve bir kelimeyi okumanın pek çok farklı yolu olduğundan bahseder (Willing, 2003). Kullanılan kelimelerin hangi kelimeler olduğundan ziyade, konuşma sırasındaki hatalar, duraklamalar, vurgulanan bölümler ve tereddütte kalınan noktalar daha önemlidir. Söylem analizi, doğallıktan yanadır, dilin incelenmesini amaçlar; araştırma sorusu temel unsurdur (Gill, 1996). Söylem analizi, diğer nitel analiz yöntemleri gibi, farklı şekillerde elde edilen verilerin (örn. doğal gelişen konuşma diyalogları) incelenebileceği bir yöntemdir. Bununla beraber, bu analizde çokça kullanılan veri toplama yöntemi görüşmelerdir (Potter, 1996). Bu çalışma kapsamında söylem analizinden gelişen "söylemsel psikoloji” bakış açısı kullanılmıştır. Söylem, söylemsel psikolojide büyük ölçüde insanların gündelik yaşantılarını yürütürken doğal olarak ortaya çıkan konuşmaların özellik ve niteliklerine; katılımcıların söylemlerini oluştururken ne yaptıklarına odaklanırken, her türden metin ve konuşma da söylem olarak anlaşllır (bkz. Potter, 2004; 2012). Deneyimler söylemsel psikolojinin özellikle üzerinde durduğu hususlardır (Willing, 2003). Buna ilaveten, Arkonaç (2014) söylemsel psikolojinin, kişilerin karşılıklı etkileşimleri nasıl idare ettiği ile ilgilendiğini de belirtmiştir. Yöntemsel açıdan bakıldı̆̆ında, söylemsel psikolojinin esnek yapısı dikkat çekmektedir. Potter (1992) söylemsel psikolojisi bakış açısıyla söylem analizi yapmanın tek bir yolu olmadığından bahseder; tek bir vakaya, ya da daha geniş bir örnekleme sahip olunabilir. Söylem analizi ile yapılan ve tek bir katılımcının yer aldığı çalışmalara bir örnek Worthman ve Troiano'nun (2016), bir lise öğrencisiyle yaptığı ve 'iyi öğrenci olmak' ile ilgilendikleri araştırmadır. $\mathrm{Bu}$ çalışmada, söylemsel psikoloji bakış açısıyla tek bir katılımcının engeli hakkında konuşurken yaptıkları (hata, dil sürçmesi, duygusal durum değişiklikleri) ve hayatını sürdürürken çevresiyle etkileşimleri ile ilgili söylemlerinin niteliği üzerine yoğunlaşırmıştır.

\section{Veri Analizi ve Sonuçlar}

\section{Yorumlayıcı Fenomonolojik Analiz}

İlk analiz yöntemi olan Yorumlayıcı Fenomonolojik Analiz sonucunda ortaya 5 üst tema çımıştır. Bunlar; (1) engel ile ilgili duygular, (2) ilişkiler, (3) algılanan ayrımcılık, (4) engeli kabul etme/engel ile başa çıkma ve (5) dün-bugün karşılaştırması `dır. Engel ile ilgili duygular üst temasının iki alt teması mevcuttur; bunlar, negatif duygular ve karmaşık duygular `dır. Algılanan ayrımcılık üst teması ise eğitim hayatı ile ilgili ayrımcılık ve iş hayatı 
ile ilgili ayrımcılık olmak üzere iki alt temadan oluşmaktadır. Aşağıda YFA analizinin sonuçları ayrıntılarıyla sunulmuştur.

\section{Engel ile İlgili Duygular}

\section{1.a. Negatif Duygular}

Lisa, engel ve engelli olmak ile ilgili negatif duygulardan bahsetmektedir, Bu

duygular çeşitlidir. Utanç, yalnızlık ya da sinir bozukluğu olarak ortaya çıkmaktadır:

“(Engelli olmanın) adil olmadığını düşünüyorum, bu durum sinirlerimi bozuyor.”

"Bazen, yardım istemek oldukça utanç verici oluyor."

“Özellikle ilkokulda çok yalnızlık hissettim.”

\section{1.b. Karmaşık Duygular}

Lisa'nın yasadığı bir diğer durum ise kafa karışıklığıdır:

"Küçükken özellikle, anlayamaz; anlam veremezdim, kafam karışırdı niye farklı olduğumla ilgili."

\section{2. İlişkiler}

Lisa (ve çevresindekiler) genellikle engeli dışlayarak ilişki kurmayı tercih etmişlerdir.

“(Arkadaşlarım) bana özel bir muamelede bulunmuyorlar.”

“(Engelim, eski erkek arkadaşımla olan) ilişkimize dahil değildi.”

"Ailem için engelli Lisa değil, sadece Lisa'yım.”

Engel herhangi bir şekilde ilişkiye dahil olduğunda çok da pozitif bir etki yaratmadı̆̆ı söylenebilir.

"Okulda bana isimler takarlardı, mesela "tavuk bacak" derlerdi."

\section{Algilanan Ayrmezhk}

Lisa, iki temel konu da ayrımcılık yaşadığını belirtmiştir. Bunlar, iş hayatı ile ilgili ve eğitim hayatı ile ilgili ayrımcılıktır. 


\section{3.a. İş hayatı ile ilgili ayrımcılık}

"Şimdiki işimde (kasiyerlik) herhangi bir ayrımcılık yaşamadım, patronum durumumu biliyor ama ben dile getirmeden dile getirmedi. Ücretim herkesle aynı. Mola sürelerim aynı.”

\section{3.b. Eğitim hayatı ile ilgili ayrımcılık}

"Okulda herkesten daha az ödev verirlerdi, ve daha az sınıf içi alıştırma. Sonra dedim ki; 'bu durum benim beynimi etkilenmiyor.' İlk başlarda 'sen bunu yapamazsın' deyip vermiyorlardı."

\section{Engeli Kabul Etme/Engel ile Başa Çıkma}

Lisa'nın basa çıkma stratejisi daha çok kabullenme seklindedir:

"Bazı şeyleri yapamamaya alıştım. Mesela çok fazla basamak çıkamamak.

"Okulda pek çok gezi oluyordu, tırmanışlar ya da su sporlarını içeren. Bunların hiç birine katılamadım. Ama şimdi daha iyiyim, bununla yaşamaya alıştım.”

\section{Dün-Bugün Karşılaştırması}

Lisa ve engel ilişkisinde zamanın getirdiği bir iyileşmeden söz edilebilir. $\mathrm{Bu}$ hem fiziksel anlamda güçlenmeye dayalı bir iyileşme hem de daha metaforik anlamda yaşanan toplumsal iyileşmenin yansımalarıdır.

"Orta okulda, ilkokula nazaran kendime daha çok güveniyordum."

"Eskiden her şey daha zordu. Şimdi, fiziksel becerilerim de arttı, örneği asansör arayışlarım azaldı.”

"Şimdi her şey daha iyi. Üniversitede kimsenin engelinden dolayı ayrımcılığa uğramaması için çalışıyorum, herkes eşit haklara sahip olmalı.”

\section{Söylem Analizi}

Söylem analizinde sorulan soru temel alınmaktadır, pek çok farklı konu etrafında gerçekleşen görüşmenin temel sorusu 'Engelli olmak nasıl bir şey?'dir. Analiz sonucunda, tüm görüşmeye yayılan iki yaygın tez ortaya çıkmıştır. Bunlar, (1) engelim beni etkilemiyor ve (2) engelli olmak adil değil savlarıdır. Katılımcı görüşme sırasında en çok bu iki konu üzerinde durmuş; konuşma sırasındaki hataları, vurguları ve duraksamaları en çok bu 
alanlarda yoğunlaşmıştır. Aşağıda söylem analizi sonucunda ortaya çıkan detaylı sonuçlar sunulmuştur; alıntılardaki köşeli parantezler katılımcının konuşma sırasındaki hata, tepki ve durmalarını, altı çizili kelimeler ise vurguladığı noktalara işaret etmektedir.

\section{Engelim Beni Etkilemiyor}

Lisa, engelinden bahsederken genellikle 'o' veya 'bu' gibi zamirleri kullanmayı tercih etmiş̧tir. Duraksadığı ve hata yaptığı yerler 'engelim beni etkilemiyor' savını destekleyecek niteliktedir.

“'O’ (Engelim) beni zihinsel olarak etkilemiyor [kelime hatası], nasıl bir insan olduğumu da etkilemiyor.”

“Erkek arkadaşım, pardon, eski erkek arkadaşım, 'onu' [durma] engelimi biliyordu ama bu ilişkimizi etkilemiyordu."

"Okulda herkesten daha az ödev verirlerdi, ve daha az sınıf içi alıştırma. [Durma] Sonra dedim ki; 'bu durum benim beynimi etkilenmiyor.' İlk başlarda "sen bunu yapamazsın” deyip vermiyorlardı."

\section{Engelli Olmak Adil Değil}

“(Küçükken) 'bu' adil değil niye diğer insanlar normal de ben değilim diye düşünüyordum. “

"Mümkün olduğunca bağımsız olmaya çalışırım. Yardım istemekten hoşlanmam. Bu konuda rahatsızlık duyuyorum [durma], çünkü bu adil değil, bu tip şeyleri [yüz ifadeleriyle sinirlendiğini belirtti] (bıçak kullanarak et kesmek gibi) kendim yapabilmeliyim.”

"Şimdi (üniversite hayatında) kendime daha çok güveniyorum; bu adil değil, engelli olmak [durma] benim suçum değil diyebiliyorum.”

\section{Tartışma}

$\mathrm{Bu}$ çalışma, engelli bir üniversite öğrencisinin engel ile ilgili deneyimlerini ve bu deneyimleri söze nasıl döktüğünü incelemeyi amaçlamaktadır. Çalışmada iki farklı nitel analiz yöntemi (yorumlayıcı fenomonolojik analiz -YFA- ve söylem analizi) bir arada kullanılarak bu yöntemlerin ortak ve farklılaşan bulguları temelinde derinlemesine bir analiz yapmak ve anlam çıkarmak hedeflenmiştir. Çalışmanın sonuçlarına bakıldığında, kullanılan iki analiz yönteminin hem benzer içerikte bulgular ortaya çıkardığı, hem de bunu yaparken kendi karakteristik özelliklerine göre farklı nokta ve durumları sergilediği görülmektedir. YFA kapsamında engel ile ilgili duygular teması kapsamında karşımıza çıkan "engelli 
olmanın adil olmadığı” savı söylem analizinde de ortaya çıkmıştır. Benzer şekilde, YFA'nın "algılanan ayrımcılık" temasında da söylem analizinde ortaya çıkan engelin adil olmayışı ile ilgili pek çok vurgu mevcuttur. Ayrıca, YFA'daki "ilişkiler" alt temasında katılımcı, üniversite eğitimi sürecindeki arkadaşlarıyla, romantik ilişkideki partneriyle ve aile üyeleriyle ilişkilerinden bahsederken ve "dün-bugün karşılaştırması” alt temasında geçmiş hayat dönemleri ve eğitim aşamalarında yaşadığı zorlukları anlatırken, söylem analizinde de ortaya çıktığı gibi şu anda geldiği noktada engelinin kendisini etkilemediği savını sıklıkla dile getirmiştir. İki analizin sonuçları karşılaştırıldığında elde edilen içerik benzerliklerin yanında, ortaya çıkan en büyük fark, olumsuzlukların, söylem analizi bakış açısıyla incelendiğinde daha çok kendini göstermesidir. Vurgu ve yanlış yüklem kullanma (örn. etkilemiyor yerine etkiliyor) gibi konuşma hataları daha çok bu kısımlarda yapılmıştır.

Araştırmanın bulguları üniversite çağındaki genç yetişkinlerin psikolojik sağlık ve iyilik hali ile ilişkili değişkenlerin ışığında tartışıldığında daha çok anlam kazanmaktadır. Daha önceki çalışmalarda gösterildiği gibi üniversite eğitimi alan genç yetişkinler için psikolojik sağlık, adaptasyon, iyilik hali ve hayat kalitesi ile ilgili bir çok faktör bulunmaktadır (örn. Koca-Atabey, vd., 2011; Martins ve vd., 2017). Bu kişilerin kişilik gelişiminin ve akademik başarılarının sağlanabilmesi için psikolojik iyilik hali ile ilişkilendirilen bazı yetkinliklerin kazandırılması yönünde uygulamalar yapılması ve müdahale programları geliştirilmesi gerektiği belirtilmiştir (örn. Gutman ve Schoon, 2015). Bu yetkinliklerden bazıları ahlaki, bilişsel, sosyal, duygusal, ruhsal ve esneklikle ilgili yetkinlikler olarak sıralanabilir. Akademik performans ile pozitif, problemli davranışlarla negatif yönde ilişkisi bulunan bazı yetkinliklerin de öz-yeterlilik, sosyal ve duygusal yetkinlik gibi yetkinlikler olduğu bulgulanmıştır (bkz., Caprara, Vecchione, Alessandri, Gerbino, ve Barbaranelli, 2011; Catalano ve vd., 2012; Roth ve Brooks-Gunn, 2003). Bu özellikler kişinin engelli olup olmamasından bağımsız; ancak engelli olmasıyla daha farklı bir tanım, anlam ve önem kazanabilecek özelliklerdir. Bu çalışma kapsamında elde edilen bulgulara bakıldığında katılımcının sosyal, duygusal bilişsel yetkinlikle ilgili örnek oluşturabilecek ifadeler kullandığı, zihinsel esneklik açısından da oldukça belirgin ve yetkin özellikler sergilediği görülmektedir. Analizlere bakıldığında YFA sonuçlarında direk üst tema isimlerinden anlaşılabilecek olan "engeli kabul etme/engel ile başa çıkma”, "engel ile ilgili duygular", bunların içeriğinde detaylı örneklendirilmiş olan daha önceki yıllardan üniversite hayatına geçiş sürecinde hissettiği utanma, yalnızlık, zamanla engelinden veya engellenmiş olma durumundan dolayı yapamadığı işler, katılamadığı aktiviteler ve süreç içinde baş etme yetisinin artması ile ilgili durumları net bir şekilde örneklendirmiş ve kendi içinde anlamlandırmış olması katılımcının psikolojik iyilik hali kapsamında değerlendirilebilen yukarıda sıralanan yetkinliklere sahip olma derecesini göstermektedir. Aynı şekilde söylem 
analizi sonuçlarına bakıldığında da engelinin kendisinin nasıl bir insan olduğunu etkilemeyen bir faktör olduğunun vurgulanması, zamanla engelli olmanın kendisiyle ilgili bir şey olmadığı noktasına geldiğini ifade etmesi ve hayatını sürdürürken zaman içinde bağımsız olma yolunda ilerleyebilmesi Lisa'nın öz-yeterlilik açısından da gelişim sürecini örneklendiren ifadeler olmuştur. Öte yandan, söylem analizi kapsamında incelendiğinde katılımcının belirli noktalarda, özellikle engelinin kendisini etkilemediğini ve engelli olmanın adil olmadığını en net şekilde ifade ettiği noktalarda, çeşitli konuşma hataları yapması, duraksaması veya sinirlendiğini belli etmesi, engelle yaşama konusundaki adaptasyon zorluğunu bu süreçteki olumsuz tecrübeleri ortaya çıkarır niteliktedir. Bu olumsuz tecrübeler katılımcının iyilik halini negatif yönde etkileyebilecek bir ortam oluşturmuştur. Bununla birlikte, sonuçları sosyal model bakış açısı çerçevesinde değerlendirdiğimizde, katılımcının yaşamı boyunca pek çok engelle karşılaştığı ve toplumun engel yaratmada oldukça cömert davrandığı söylenebilir. Toplum hem eşit katılım noktasında problemler yaratmış hem de Lisa'nın pek çok olumsuz duyguyla karşılaşmasına zemin hazırlamıştır. Şartlar ve zaman, alan yazınında engel ile ilgili olarak vurgulanan iki önemli husustur (örn. Schillmeier 2008; Koca-Atabey, 2017). Bu iki kavramda Lisa'nın lehine işlemiş ve engelin kendisinden kaynaklanmadığı sonucuna ulaşmıştır.

Çalışma kapsamında iki farklı nitel analiz tekniğinin kullanılması elde edilen bulguların farklı yöntemlerle incelendiğinde nasıl bir örüntü sunacağını göstermiştir. Kullanılan YFA ve söylem analizi teknikleri bu çalışmada birbiriyle uyumlu ve bazı açılardan örtüşen sonuçlar sunmuştur; fakat bu durum iki analiz tekniğinin birbirinin tekrarı olduğu anlamına gelmemektedir. Bu noktada nitel analizdeki araştırmacının analizlerin karakteristik özelliklerine odaklanarak veriyi yorumlayışı öne çıkar. Unutulmamalıdır ki, YFA'da da, söylem analizinde de öznellik esastır. O nedenle eğer bir araştırmacı bir çalışma kapsamında katılımcıların ne dediğiyle daha çok ilgileniyorsa YFA'yı; nasıl dediğini de vurgulamayı hedefliyorsa söylem analizini seçmelidir. Hiç kuşkusuz YFA ve söylem analizindeki benzerlikler ya da farklılıklar ile ilgili derinlemesine teorik bir tartışma yapmak daha kapsamlı çalışmalar gerekecektir. Bu araştırma, YFA ve söylem analizi yöntemlerinin bir arada kullanması ve bu şekilde farklı durumsal ve etkileşimsel yaşam deneyimlerini farklı noktalara odaklanarak bir araya getirmesi açısından alanyazına anlamlı bir katkı sağlayıp ileride yapılacak benzer çalışmalara örnek ve alt yapı oluşturabilecek bir çalışmadır. Nitel analizde farklı yöntemin bu çalışmada olduğu şekliyle bir arada kullanılması yaygın bir durum olmasa da, bu çalışma gibi tek katılımcının dahil olduğu bir çalışma bu tür bir uygulama için uygun bir zemin olarak düşünülmüştür. Özellikle veri analizi sırasında oluşacak içeriğin yoğunluğunun getireceği karışıklık ve sonuçların karşılaştırılmasında çıkabilecek zorluklar gibi sebeplerle bu tür bir çalışmayı daha fazla sayıda kişinin katılımcı 
olduğu bir yapıda uygulamak mümkün olmayabileceği düşünülmüsş, bu çalışmanın bu yöntemle özellikle tek kişinin katılımcı olacağı bir şekilde kurgulanması da bu sebebe dayanmıştır.

Bu çalışma kapsamında, farklı yöntemlerin kullanımına ek olarak araştırmacıların ve katılımcının farklı deneyimlerinin de ortaya çıkan etkileşimi zenginleştirdiği düşünülmektedir. Bu çalışmada araştırmacıların deneyimleri ile ilgili değinilmesi gereken bir husus araştırmacıların engel araştırmaları ile ilgili önceki deneyimlerdir (örn., Bakır ve Öz, 2016; Koca-Atabey, 2013; Koca-Atabey ve Öz, 2017). Bu deneyimler tüm nitel verinin yorumlanmasında etkili olmuştur.

$\mathrm{Bu}$ araştırma ile ilgili önemli bir unsur katılımcının ve araştırmacıların anadil farklılığıdır. Bu durum veri kaybına yol açmış olabilir. Ayrıca, araştırmacılar ve katılımcı farklı kültürden yetişmiş ve dolayısıyla engel ile ilgili farklı kavramsallaştırmalara sahiptirler. $\mathrm{Bu}$ farklılıklar, her ne kadar veri kaybına ve kavramsallaştırma farklılıklarına potansiyel zemin hazırlasa da, engel olgusunu anlamak yönünde bir zenginlik oluşturabileceği de düşünülmektedir.

Tek katılımcının detaylı analizine dayanan bu çalışmanın sonunda engelli üniversite öğrencilerinin deneyimlerinin onların şu anda bulundukları nokta ve süreçsel olarak geçtikleri yoldaki yaşantılarının belirgin ve anlamlı içeriklerle gruplanabileceği ortaya çıkmıştır. Bu gruplamanın psikolojik sağlık ve iyilik hali ile ilgili değişkenlerle bağlantılı özellikler sergilediği görülmüş̧tür. Bu bulgular, üniversite eğitimi alan engelli öğrencilerin gelişimsel süreçteki ve engel özelliklerine göre yaşadıkları deneyimler bazında ileriki çalışmalara konu olmaya devam etmesinin gerekli ve önemli olduğunu göstermiştir. Bunun en büyük nedeni, "pastanın kreması" olan bu katılımcıların, deneyim ve yetkinliklerinin anlaşılması yoluyla müdahale ve önleme programlarına bilhassa da eğitim konusuna ışı tutabilecek olmalarıdır. Engelin anlamlandırılmasının kültürel bir olgu olduğu düşünülecek olursa bu tür çalışmaların ülkemizde yapılması ve sonuçlarının kültürel özellikler temelinde çeşitli uygulamalara yansıtılabilmesi hem engelli hem engelsiz kişilerin sağllklı etkileşimine ve psikolojik sağlıkla ilgili tüm yetkinlikler konusunda gelişimine katkıda bulunma potansiyelindedir. Türkiye'de engel, tam da Shakespeare in (2008) tanımladığı gibi karmaşık bir beladır. Ayrıca, engel ile ilgili kırılması çok güç bir kısır döngü de mevcuttur (KocaAtabey, 2016) ve belki de çözüme yardımcı olabilecek en önemli husus da yaşanmış deneyimlere ve o deneyimlerin söze nasıl döküldüğüne kulak vermektir. 


\section{Kaynakça}

Arkonaç, S. A. (2014) Psikoloji ve söylem çalışmaları. Eleştirel Psikoloji Bülteni, 39-54.

Barnes, C. (2007). Disability, higher education and the inclusive society. British Journal of Sociology of Education, 28(1), 135-145.

Barnes, C. ve Mercer, G. (2003). Disability. UK: Polity Press.

Bakır, A. B. (2016). An Investigation and Comparison of Human Factors inDriving and Attitudes Towards Disabled Drivers: A Study with Disabled and Non-Disabled Drivers. (Yayımlanmamış Yüksek Lisans Tezi). Orta Doğu Teknik Üniversitesi, Ankara, Türkiye.

Bakır, A. ve Öz, B. (2016). Trafikte engelli sürücülere yönelik tutumlar: Mülakat sonuçlarının içerik analizi. Sürdürülebilir Ulaşım İçin Yol ve Trafik Güvenliği Kongresi (ROTRASA) Bildiri Kitabı.

Brunsden, V. ve Hill, R. (2009). Firefighters' experience of strike: An interpretative phenomenological analysis case study. The Irish Journal of Psychology, 30(1-2), 99-115.

Caprara, G. V., Vecchione, M., Alessandri, G., Gerbino, M., ve Barbaranelli, C. (2011). The contribution of personality traits and self-efficacy beliefs to academic achievement: A longitudinal study. British Journal of Educational Psychology, 81(1), 78-96.

Catalano, R. F., Fagan, A. A., Gavin, L. E., Greenberg, M. T., Irwin, C. E., Ross, D. A., ve ark. (2012). Worldwide application of prevention science in adolescent health. Lancet 379(9826), 16531664 .

Damianakis, T. ve Woodford, M. R. (2012). Qualitative research with small connected communities: Generating new knowledge while upholding research ethics. Qualitative Health Research, 22(5), 708-718.

Davis, L. ve Green, J. (1999). Living disability: A conversation. Social Alternatives, 18(1), 18-23.

Dökmen, Z. Y. ve Tutarel-Kışlak, Ş. (2004). Engelli olan ve olmayan üniversite öğrencilerinin demografik ve psikolojik özellikleri ile sorunlarının karşılaştırılması. Kriz Dergisi, 12(2), 3347.

Edwards, D., \& Potter, J. (1992). Discursive psychology. London: Sage.

Eisenberg, D., Golberstein, E., ve Hunt, J. B. (2009). Mental health and academic success in college. B.E. Journal of Economic Analysis and Policy, 9. Article 40.

French, S. (2004). Can you see the rainbow? The roots of denial. J. Swain, S. French, C. Barnes, ve C. Thomas, (Eds). Disabling barriers-enabling environments (ss. 81-86). London: Sage Publications.

French, S. ve Swain, J. (2004). Controlling inclusion in education: Young disabled people's perspectives. J. Swain, S. French, C. Barnes ve C. Thomas, (Eds). Disabling barriers-enabling environments (ss. 169-175). London: Sage Publications.

Fuller, M., Healey, M., Bradley, A., ve Hall, T. (2004). Barriers to learning: A systematic study of the experience of disabled students in one university. Studies in Higher Education, 29(3), 303318.

Ghaemi, S. N. (2009). The rise and fall of the biopsychosocial model. British Journal of Psychiatry, 195(1), 3-4.

Gutman, L. M. ve Schoon, I. (2015). Preventive interventions for children and adolescents: A review of meta-analytic evidence. European Psychologist, 2O(4), 231-241. 
Gill, R. (1996). Discourse analysis: Practical implementation. J. T. E. Richardson, (Ed). Handbook of qualitative research methods for psychology and the social sciences (ss. 141-156). Leicester: British Psychological Society.

Goode, J. (2007). 'Managing' disability: Early experiences of university students with disabilities. Disability and Society, 22(1), 35-48.

Hammersley, M. (1996). The relationship between qualitative and quantitative research: Paradigm loyalty versus methodological eclecticism. J. T. E. Richardson, (Ed). Handbook of qualitative research methods for psychology and the social sciences (ss. 159-174). Leicester: British Psychological Society.

Holloway, S. (2001). The experience of higher education from the perspective of disabled students. Disability and Society, 16(4), 597-615.

Hopkins, L. (2011). The path of least resistance: A voice- relational analysis of disabled students' experiences of discrimination in English universities. International Journal of Inclusive Education, 15(7), 711-727.

Humber, L. A. (2014). Social inclusion through employment: the marketisation of employment support for people with learning disabilities in the United Kingdom. Disability and Society, 29(2), 275-289.

Koca-Atabey, M. (2013). A personal validation of the social nature of disability: Different environments, different experiences. Disability and Society, 28(7), 1027-1031.

Koca-Atabey, M. (2016). Yeşilçam’da körlüğün temsili: Trajik, tıbbi ve zamansız. Klinik Psikoloji Dergisi, 3(1), 16-27.

Koca-Atabey, M. (2017) Re-visiting the role of disability coordinators: The changing needs of disabled students and current support strategies from a UK university. European Journal of Special Needs Education, 32(1), 137-145.

Koca-Atabey, M., Karanc1, A. N., Dirik, G., ve Aydemir, D. (2011). Psychological well-being of Turkish university students with physical impairments: An evaluation within the stress-vulnerability paradigm. International Journal of Psychology, 46(2), 106-118.

Koca-Atabey, M. ve Öz, Bahar. (2017). Telling about something that you do not really know: Blind people are talking about vision! Disability and Society, 32(10), 1656-1660.

Laes, T. ve Westerlund, H. (20018). Performing disability in music teacher education: Moving beyond inclusion through expanded professionalism. International Journal of Music Education, 36(1), 34-46.

Mayers, C., Leavey, G., Vallianatou, C., ve Baker, C. (2007). How clients with religious or spiritual beliefs experience psychological help-seeking and therapy: A qualitative study. Clinical Psychology and Psychotherapy, 14(4), 317-327.

Morris, J. (1991). Pride against prejudice. Transforming attitudes to disability. London: Women`s Press.

Morris, J. (1993). Independent lives. Community care and disabled people. London: Macmillan Press.

Morse, J. M. (1998). The contracted relationship: Ensuring protection of anonymity and confidentiality. Qualitative Health Research, 8(3), 301-303.

Ong-Dean, C. (2005). Reconsidering the social location of the medical model: An examination of disability in parenting literature. Journal of Medical Humanities, 26(2-3), 141-158. 
Oliver, M. (1996). Understanding disability: From theory to practice. New York: St Martin's Press.

Pietkiewicz, I. ve J. A. Smith (2014). A practical guide to using Interpretative Phenomenological Analysis in qualitative research psychology. nomenological Analysis. Czasopismo Psychologiczne - Psychological Journal, 20(1), 7-14.

Potter, J. (1996). Representing reality: Discourse, rhetoric and social construction. London: Sage Publications.

Potter, J. (2004). Discourse analysis as a way of analysing naturally occurring talk. In D. Silverman (Editor),Qualitative research: Theory, method andpractice (pp. 200-222). London: Sage.

Potter, J. (2012). Discourse analysis and discursive psychology. In: H. Cooper (Editor). APA handbook of research methods in psychology: Quantitative, qualitative, neuropsychological, and biological (pp. 111-130). Washington: American Psychological Association Press.

Poussu-Olli, H. S. (1999). To be a disabled university student in Finland. Disability and Society, 14(1), $103-113$.

Priestly, M. (2003). Disability. A life course approach. Oxford: Blackwell Publishers.

Pringle, J., Drummond, J., McLafferty, E., ve Hendry, C. (2011). Interpretative phenomenological analysis: A discussion and critique. Nurse Researcher, 18(3), 20-24.

Redpath, J., Kearney, P., Nicholl, P., Mulvenna, M., Wallace, J., ve Martin, S. (2013). A qualitative study of the lived experiences of disabled post-transition students in higher education institutions in Northern Ireland. Studies in Higher Education, 38(9), 1334-1350.

Roth, J. L., ve Brooks-Gunn, J. (2003). Youth development programs: Risk, prevention and policy. Journal of Adolescent Health, 32(3), 170-182.

Schillmeier, M. (2008). Time-spaces of in/dependence and dis/ability. Time and Society 17 (2/3), 215-231.

Shakespeare T. (2008). Disability: Suffering, social oppression, or complex predicament? M. Düwell, C. Rehmann-Sutter, ve D. Mieth (Eds), The contingent nature of life: Bioethics and limits of human existence (ss. 231-241). Heidelberg: Springer.

Smith, J. A. (1996). Beyond the divide between cognition and discourse: Using interpretative phenomenological analysis in health psychology. Psychology and Health, 11(2), 261-271.

Smith, J. A. (2011). Evaluating the contribution of interpretative phenomenological analysis. Health Psychology Review, 5(1), 9-27.

Smith, J. A., Jarman, M., ve Osborn, M. (1999). Doing interpretative phenomenological analysis. M. Murray ve K. Chamberlain (Éds), Qualitative Health Psychology: Theories and methods (ss. 218-240). London: Sage Publications.

Smith, J. A. ve Osborn, M. (2003). Interpretative phenomenological analysis. J. A. Smith (Ed), Qualitative psychology. A practical guide to research methods (ss. 51-80). London: Sage Publications.

Soorenian, A. (2013). Housing and transport: access issues for disabled international students in British universities. Disability and Society, 28(8), 1118-1131.

Taylor, S. J. ve Bogdan, R. (1998). Introduction to qualitative research methods: A guidebook and resource. New York: Wiley. 
UPIAS [Union of the Physically Impaired Against Segregation]. (1975). Fundamental principles. Erişim adresi: http://disability-studies.leeds.ac.uk/files/library/UPIAS-fundamentalprinciples.pdf

Whittington, A. ve Burns, J. (2005). The dilemmas of residential care staff working with the challenging behaviour of people with learning disabilities. British Journal of Clinical Psychology, 44(1), 59-76.

WHO [World Health Organization]. (2002). International classification of functioning, disability and health: ICF. Geneva: World Health Organization.

Willing, C. (2001). Introducing qualitative research in psychology. Adventures in theory and method. London: Sage Publications.

Willing, C. (2003). Discourse Analysis. J. A. Smith (Ed), Qualitative psychology. A practical guide to research methods (ss. 159-183). London: Sage Publications.

Worthman, C. ve Troiano, B.(2016). A good student subject: A Foucauldian discourse analysis of an adolescent writer negotiating subject positions. Critical Studies in Education, DOI: $\underline{10.1080 / 17508487.2016 .1246372}$

Wynaden, D., Wichmann, H., ve Murray, S. (2013). A synopsis of the mental health concerns of university students: results of a text-based online survey from one Australian university. Higher Education Research and Development, 32(5), 846-860.

Zambo, D. (2004). Using qualitative methods to understand the educational experiences of students with dyslexia. Qualitative Report, 9(1), 80-94. 


\section{The experiences of a disabled university student: An evaluation with two different analysis methods}

\section{Summary}

The literature consists of different perspectives relating disability. The most known models are the medical model, social model and biopsychosocial model. Medical model argues that disability is an illness and should be treated by the clinicians. Biopsysocial model aims an eclectic perspective and has a more is better point of view. This study is conceptualized within the social model perspective, which argues that disability is a fact of life; a different life experience and it might also be interesting and affirmative. It is not the impairment but the society that disables people. The current study aimed to investigate the experiences of a disabled university student. The participant was a 19-year-old female who is studying history. Her psydenoum was Lisa and she is from the UK. Initially a 55-minutes interview was conducted and transcribed verbatim. Afterwards, two different qualitative methods namely interpretative phenomenological analysis -IPA- and discourse analysis were conducted. IPA aims to investigate how the participants are making sense of the personal and social world by taking its three theoretical underpinnings as the base: phenomenology, hermeneutics, and ideography. IPA is flexible concerning sample size and favours homogenous and purposive sampling. On the other hand, discourse analysis evaluates language within the context and argues that there is more than one way to evaluate a word. The current study adopts the discursive psychology framework. Discursive psychology investigates how participants use language to negotiate and manage social interactions. Experience is an important element of discursive psychology; it also favours flexibility. According to the results, IPA revealed the following five superordinate themes: (1) emotions related to disability, (2) relations, (3) perceived discrimination, (4) accepting disability/coping with disability and (5) comparison of yesterday and today. Discourse analysis revealed two important discourses: (1) my disability is not affecting me and (2) being disabled is not fair. The two abovementioned methods revealed similar results focusing on different aspects of being a disabled university student. For instance, both IPA and discourse analysis revealed that 'it is not fair to be disabled person.' Both IPA and discourse analysis have a subjective nature. On the other hand, the results of the discourse analysis revealed more negativity in the way that the participant mentioned about her experiences. The overall results showed that, if the researcher aims to deal with the content, s/he should choose IPA. If the process of producing that content is much more important to the researcher, then discourse analysis should be preferred. From a social model perspective, we might discuss 
that Lisa was extensively disabled by the society. There were issues related to equal participation, which may lead up to negative emotions. On the other hand, both the context and time favoured her and she came to the point that she is not the source of disability; the main source of disability is the society. Studies, especially the qualitative ones, relating disabled university students should be continued in order to provide the literature with detailed understanding of this group of students and find ways to improve their wellbeing. This need is crucial as the disabled students are the cream of the crop at university settings. Additionally, deeper analyses might be necessary to discuss the similarities and differences between IPA and discourse analysis. The present research should be considered a pilot study emphasizing this need within its framework. 